\title{
Healthcare access and quality of birth care: narratives of women living with obstetric fistula in rural Tanzania
}

\author{
Lilian T. Mselle ${ }^{1 *}$ and Thecla W. Kohi ${ }^{2}$
}

\begin{abstract}
Background: Increasing births with skilled attendants and increasing health facilities with Emergency Obstetric Care (EmOC) can reduce maternal mortality and are considered critical interventions for ensuring safe motherhood. Despite Tanzania's policy to support women to give birth with the assistance of skilled personnel, some women do not access this care. This article uses women's stories to illustrate the challenges that caused them to fail to access adequate obstetric care in a timely manner, hence causing the development of fistulas.

Methods: This paper presents the narratives of 16 women who were conveniently selected based on their experiences of not being able to access adequate obstetric care in timely manner. The analysis was guided by recommendations for the identification and interpretation of narratives, and identified important components of women's experiences, paying attention to commonalities, differences and areas of emphasis. Semi-structured interviews were carried out at CCBRT hospital in Dar es Salaam.

Results: Four (4) general story lines were identified from women description of their inability to access quality obstetric care in a timely manner. These were; failing to decide on a health care facility for delivery, lacking money to get to a health care facility, lacking transportation to a health care facility and lacking quality birth care at the health care facility.

Conclusion: Women were unable to reach to the health care facilities providing comprehensive emergency obstetric care (CEmOC) in time because of their lack of decision-making power, money and transportation, and those who did reach the facilities received low quality birth care. Empowering women socially and financially, upgrading primary health care facilities to provide CEmOC and increased numbers of skilled personnel would promote health care facility deliveries.
\end{abstract}

Keywords: Obstetric fistula, Emergency obstetric care, Women's birth care, Narratives, Tanzania

\section{Background}

Increasing births with skilled attendants and increasing the number of health facilities with Emergency Obstetric Care $(\mathrm{EmOC})$ can reduce maternal mortality and are critical interventions for ensuring safe motherhood. These resources help ensure the timely provision of emergency obstetric and new-born care when lifethreatening complications arise [1]. Approximately $60 \%$

\footnotetext{
*Correspondence: nakutz@yahoo.com

'Department of Clinical Nursing, Muhimbili University of Health and Allied

Sciences, PO Box 65004, Dar es Salaam, Tanzania

Full list of author information is available at the end of the article
}

of maternal deaths occur during labour, delivery and the immediate postpartum period, with $50 \%$ of these deaths occurring within the first $24 \mathrm{~h}$ of delivery [2]. Tanzania is a sub-Saharan African country with unacceptably high numbers of maternal morbidities, including obstetric fistula, and deaths, with an estimated maternal mortality ratio of more than 300 per 100,000 live births [3]. Maternal deaths are commonly caused by postpartum haemorrhage, obstructed labour, eclampsia, sepsis and abortion complications $[4,5]$, and previous studies have reported that approximately $15 \%$ of all pregnant women will 
develop pregnancy and childbirth related complications that require prompt access to EmOC $[6,7]$.

Attendance to antenatal care, delivery in a medical setting and having skilled health personnel at delivery are key health care interventions that can largely prevent women from dying of pregnancy related causes and improve maternal and neonatal outcomes $[8,9]$. While approximately $98 \%$ of pregnant women attend antenatal clinics (ANC) for check-ups at least once, only $50 \%$ give birth in health facilities, and among these, only $51 \%$ are attended by skilled health personnel [10]. Tanzania's government implemented various interventions to reduce maternal mortality, including reproductive and child survival, increased skilled delivery, maternal death audit, coordination and integration of different programs such as maternal and child health services, family planning, malaria interventions, expanded program on immunization and adolescent health and nutrition programmes. These initiatives are, however, challenged by an inadequate number of women who seek maternal health services because many women still give birth in homes. Women do not seek adequate obstetric care because of distance to the health facilities that provide EmOC, their low socioeconomic status and cultural factors, institutional cost, limited material and supplies in the facility, attitudes and competence of health care providers, and lack of staff managerial support [6, 11-13].

Poor access to EmOC is associated with negative maternal and neonatal outcomes. One of the outcomes of poor access to EmOC during childbirth is disabling obstetric complications, the most disabling of which is obstetric fistula. Each year, obstetric fistula affects more than 100,000 women worldwide [14] and more than 2500 women and girls in Tanzania [15]. It occurs when labour is allowed to progress for periods lasting from several days to a week, where the foetal head exerts pressure on surrounding soft tissues, which results in necrosis and the concomitant creation of an opening through which urine and/or faeces leak [16].

At the personal level, women living with obstetric fistula experience multiple losses [17], including physical problems, social exclusion and economic decline $[15,18]$. The disability that women acquire from the resulting smell, sores, infection, and inability to control the leaking of urine leave them unable to assume their ascribed social and marital roles [17]. Families and the community often exclude women living with fistulas $[15,18-20]$. They experience a severe reduction in their independent income, which results in increased dependence on others [20,21].

Studies on obstetric fistula in Tanzania have addressed issues related to social vulnerability $[15,22]$, experiences of birth care [12], perceived causes of obstetric fistula $[23,24]$, experiences of living with fistula $[17,25]$, religious coping of obstetric fistula [26] and women's reintegration after fistula repair [27, 28]. This study uses women's stories to illustrate their experience of failing to access adequate obstetric care and the challenges they faced during labour and delivery that caused an obstetric fistula. Understanding these experiences will guide the development of strategies to increase health facility deliveries in Tanzania.

\section{Model}

The fundamental construct in understanding the cause of maternal deaths is the "three delays" model developed by Thaddeus and Maine [29]. These are (1) delay in recognising danger signs/decision to seek care, (2) delay in reaching a medical facility and (3) delay in receiving appropriate care once a facility is reached. We adopted the "three delays" model as a framework for describing women's stories of their experiences of labour and delivery, particularly regarding how failure to promptly access adequate obstetric care led to the development of a fistula. This model provides a valuable theoretical foundation for examining composite interactions between women's ability to make decisions on where to go for delivery, problems they encounter in reaching an adequate EmOC facility and receiving adequate obstetric care at the facility. In addition, it identifies key time periods in pregnancy and childbirth during which delays that have direct consequences on both maternal and neonatal survival can occur.

\section{Methods}

This study uses narrative research, a qualitative approach on the propensity of humans to narrate experiences, and draws on data from a previous study on access to and quality of birth care in Tanzania: The problem of obstetric fistula and its implication conducted between 2010 and 2012 [30]. Stories provide a way for individuals to reflect on their experiences, create meaning, and imagine life's possibilities [31]. They are concrete, personal and temporal accounts in which the narrator sets the scene and describes the main event and their resolution, including the central point of the story. In this study, stories from an in-depth analysis of women's experience of labour and delivery provide a way to understand the complexities inherent in how women who live in rural settings of Tanzania access adequate obstetric care. By identifying the main story lines, a rich description of labour and delivery in the context of women's lived experience of delays in accessing adequate obstetric care is provided [32]. The usefulness of stories in enriching our understanding of health and illness experiences has been recognised [31]. 


\section{Setting}

As described elsewhere [25], the study was conducted at the Comprehensive Community Based Rehabilitation in Tanzania (CCBRT) hospital. CCBRT is a private, nongovernmental organisation (NGO) in Dar es Salaam that serves as a major service delivery point for obstetric fistula repair in the Coastal region. It also receives patients from the central and eastern part of the country. The hospital has a 21-bed fistula ward, and a hostel where fistula patients live while awaiting fistula repair. It performs approximately 400 vesico-vaginal fistula (VVF) and recto-vaginal fistula (RVF) surgeries each year. The hospital has an active case finding program that traces patients in rural areas and brings them to the hospital for surgical treatment free of charge. This is done using a mobile phone based money transfer service to send cash to obstetric fistula patients for transportation costs to come to CCBRT. The program is facilitated by health care providers working in the primary health care facilities, who identify, communicate and facilitate transportation of women with obstetric fistula to CCBRT for treatment. The hospital also implements an incentive scheme for the identification of obstetric fistula cases.

\section{Participants}

A convenience sample of 16 women affected by obstetric fistula was recruited for semi-structured interviews. It was essential to use convenience sampling because women were recruited from the fistula ward, and some were recruited after fistula repair. Therefore, their recruitment depended on their health condition. The inclusion criteria were women with fistula admitted to CCBRT for surgical repair (before or after fistula repair), ability to speak Kiswahili and willing to participate in the study. A senior nurse-midwife in the fistula ward aided in identifying women who met the inclusion criteria, explained the purpose and the method of the study, including principles of confidentiality, and arranged for a suitable time for an interview. All participants provided written informed consent.

\section{Data collection}

Each woman participated in an audio recorded, semistructured interview [33] that lasted about $1 \mathrm{~h}$. During the interviews, women were encouraged to tell their stories of labour and delivery before they developed fistula. These interviews were conducted by the first author in the room adjacent to fistula ward. The interview room was quiet and out of sight and hearing range of other fistula patients and staff; this ensured the women's privacy. The principle of saturation guided the sampling process. Saturation was achieved after 16 interviews, at which point answers from the women seemed to repeat information gained earlier and little new information was attained [34].

The semi-structured interview guide included topics and probing questions focussing on women's experiences of labour and delivery (see Table 1). The interviewer used additional probing questions to clarify aspects of stories where necessary. Prompts and probes were used to encourage women to extend their responses and to provide stories that are more complete. Most of the participants spoke openly during all interviews.

\section{Data analysis}

Data analysis was guided by recommendations for the identification and interpretation of narratives [35]. The audio recorded interviews were transcribed and read several times to identify the parts of the interview that made up each woman's story. In this stage, the audio recorded interviews were reviewed to verify the written/ transcribed interviews. Relevant sections of the interview were marked accordingly. These were all texts that described women experiences of delay in accessing obstetric care. The interviews were re-read to capture the universal impression of each woman's story. To facilitate

Table 1 Semi-structured interview guide for women affected by fistula

\begin{tabular}{l} 
1. Social and demographic background \\
- Before/After repair......... \\
_ How old are you..................... \\
— What is your education level? Did you proceed after primary school? \\
— What do you do for a living? \\
— Where do you live? \\
— Who shares a house with you? Are you married? \\
2. Obstetric history \\
— How old were you when you got pregnant the first time? How \\
many times have you been pregnant? How old were you when \\
you got pregnant the last time? Was this last pregnancy your first \\
pregnancy? \\
3. Can you please tell me about your last pregnancy? \\
— Probe: Did you attend antenatal clinic? Did you get the services \\
you expected? Where did you plan to give birth? How far was it \\
from your home? How did you plan to get there? Did you have \\
any problems during your pregnancy? Who did you seek advice \\
from during pregnancy? \\
4. Can you please tell me about the last time you gave birth? \\
— Probe: How long did it take from the onset of labour pains until \\
the child was out? Where were you when labour started? How \\
long did it take you to seek health care after you started labour? \\
What were the reasons for delay? Where did you go first? Who \\
made a decision as to where to go to seek help? What were the \\
constraints/barriers/problems in the process of seeking birth care? \\
Where did you finally deliver? How was your delivery conducted? \\
Who assisted you? Who was present during labour? When you or \\
the ones that assisted you realised that the baby did not come \\
out as expected? What action was taken? What happened after \\
the delivery? Did you go home? Did you remain in the hospital? \\
\hline
\end{tabular}


this, the author prepared brief summaries of each woman's narrative, highlighting general impressions, as well as unusual features, of each story. The authors systematically reviewed summaries of the stories to identify the central narrative or story lines that women used to explain their experiences of being unable to access obstetric care during labour and delivery (See Table 2). Decisions were made through consensus and in cases of disagreements, the authors returned to the transcript to ensure interpretations were grounded in the data. Using these central narratives, the interviews were re-read and coded.

The authors then probed each central narrative [35], whereby the process began by reading all relevant coded segments. Attention was given to the identification of important components of the stories, what was emphasized and the similarities and differences in the way the stories were told. All texts from the interviews were first analysed for identification of delay patterns in accessing obstetric care. Women's narratives were organised according to the "three delays" model [29]. The research team crosschecked analysis and discussed and agreed on the sorting of codes and naming of categories.

\section{Results}

The 16 women who participated in this study were between 19 and 43 years of age. Most of the women lived in rural areas $(82 \%)$ and had no or primary education $(88 \%)$. All of the women were unemployed (See Table 3).

In the analysis of women's experiences of labour and delivery and reasons for their inability to access adequate obstetric care in a timely manner, four (4) general story lines were identified: (1) failing to decide on a health care facility for delivery, (2) lacking money to get to a health care facility, (3) lacking transportation to a health care facility and (4) lacking quality birth care at the health care facility.

\section{Failing to decide on a health care facility for delivery}

The basic story line in the narrative of failing to decide for health facility delivery is:"usually in the village decisions on where to go for delivery is made by husbands, and if you are not married or you are without a partner, elders and parents, make decision on when and where to go for delivery". In this study, husbands, mothers-inlaw, uncles and grandmothers made decisions on where women could seek obstetric care.

Women who delivered at home had attended antenatal clinics regularly for check-ups and intended to give birth in the health care facility. However, because their husbands and mothers-in-law had decided that the women should give birth at their homes, they had no other option. Husbands and mothers-in-law made decisions for home deliveries due to costs and customs. Most of women started labour while their husbands were not around, and therefore, their mothers-in-law and uncles made the decisions to wait and give birth at home with the assistance of traditional birth attendants (TBA), who are usually present in the village and were well known.

"... My mother told my uncle that I am sick, and then he said that she (mother) has to call the traditional birth attendant" (Single, aged 18, Mseta-Dodoma).

"... My mother-in-law said I should wait as I could deliver at home. You know in the village people do deliver in homes" (Single, aged 35, Kisongo-Kilwa).

\section{Lacking money to get to a health care facility}

The basic story line of lacking money to get to a health care facility within the women's narratives occurred as follows: "I was advised by nurses to go to the major hospital. However, the day labour pains started my father had no cash...". "We did not have cash, fare...". Many women who participated in this study resided in remote rural areas. In these areas, health care facilities providing EmOC are far away and public transportation is limited. When transportation is available, women have to spend money to reach to an adequate health care facility for delivery, a cost that is too expensive for an ordinary woman in the village to afford. Therefore, women were unable to go to the health facilities because they did not have enough money to pay for transportation costs. Some women admitted that despite being informed during ANC visits to go to a health care facility for delivery, they gave birth at home because they lacked money for transportation:

Table 2 Example of the process of analysis

\begin{tabular}{ll}
\hline Summaries of women's narratives & Central narrative or story line \\
"I was advised by nurses to go to the major hospital. However, the day labour pains started my father had no cash." & Lacking money to get to health \\
facilities
\end{tabular}


Table 3 Characteristics of women affected by obstetric fistula

\begin{tabular}{|c|c|c|c|c|c|}
\hline Woman & Age & Marital status & Years in school & Duration with fistula & Domicile \\
\hline 1 & 19 & Single & 7 & 4 months & Matombo, Morogoro \\
\hline 2 & 25 & Married & 3 & $>1$ year & Handeni, Tanga \\
\hline 3 & 35 & Single & 7 & 18 years & Kisongo, Kilwa \\
\hline 4 & 20 & Divorced & 7 & 6 months & Mlandizi, Pwani \\
\hline 5 & 28 & Married & 12 & 2 months & Temeke, Dar es Salaam \\
\hline 6 & 30 & Married & 12 & 3 months & Iringa road, Iringa \\
\hline 7 & 33 & Divorced & 7 & 19 years & Mbori, Dodoma \\
\hline 8 & 29 & Divorced & 0 & 10 years & Ifakara, Morogoro \\
\hline 9 & 35 & Married & 7 & 2 years & Manyoni, Singida \\
\hline 10 & 40 & Married & 7 & 1 year & Mpwapwa, Dodoma \\
\hline 11 & 43 & Separated & 7 & 20 years & Rundi, Dodoma \\
\hline 12 & 40 & Single & 7 & 20 years & Manyoni, Singida \\
\hline 13 & 25 & Divorced & 7 & 8 months & Iringa \\
\hline 14 & 28 & Divorced & 7 & 12 years & Mvumi, Dodoma \\
\hline 15 & 29 & Divorced & 0 & 9 years & Kibakwe, Dodoma \\
\hline 16 & 18 & Single & 0 & 3 months & Mseta, Dodoma \\
\hline
\end{tabular}

"I was asked to deliver at the hospital but it was not possible because I did not have cash and I did not know where I would get the money to go there. As peasants, our income as you know are very little ... we did not have money" (Married, age 35, ManyoniSingida).

"... it is only that my husband did not secure enough money" (Married, aged 40, Mpwapwa, Dodoma).

The bus fare was also too expensive for an ordinary woman who lived in a rural area to afford:

"... It is very far. You cannot walk. You have to take a bus, and the bus fare is 5500 shillings and if you are two it will be 11,000/= (about \$ 5)" (Married, aged 35, Manyoni-Singida).

"From the village where we lived is about 178

kilometres and the bus fare is expensive, about 21,000 Tshs (about \$10) we could not afford" (Married, aged 25, Handeni-Tanga).

\section{Lacking transportation to a health care facility}

Lack of money was not the only reason for women giving birth at their homes. Women were unable to go to the health facilities for birth care because they could not get transportation to these health care facilities:
"... labour pains started while I was at home which is far, ... there were no means of transport, even bicycles or push carts. ... it was not possible for me to walk to the hospital when the baby's head was already protruding out ..." (Married, aged 35, Manyoni-Singida).

Others got to the health facility after substantial delay:

"We had to cross the river by boat, it took us $8 \mathrm{~h}$ to get to main hospital by then the baby was already dead... (crying...)" (Single, aged 19, Matombo-Morogoro).

Because of lack of transportation or the inability to pay for transportation costs, some women had to walk for many hours to get to the nearest health care facility providing CEmOC:

"It took long time to get to the hospital ... I am not sure, may be 8 h" (Separated, aged 43, RundiDodoma).

"The hospitals are far. We had to walk...It was a long walk, after a 2-hour hard walk along the way, I felt as if something had ruptured in the abdomen and immediately started vaginal bleeding" (Divorced, age 28, Mvumi-Dodoma).

\section{Lacking quality birth care at the health care facility}

The availability of skilled attendant personnel is pivotal for the provision of high quality health care. Women in 
this study reported that doctors in the primary health care facilities were not available to refer women to the health care facilities providing EmOC when labour did not progress well. A woman who lived with obstetric fistula for 19 years told her story of having to wait in the health care facility for $24 \mathrm{~h}$ before the doctor could see her:

"When we got to the dispensary nurses told me to wait. At 8 pm labour pains became intense, I started pushing but the baby could not come out, and the doctor was not around. Next day I continued pushing the whole day again until at around $8 \mathrm{pm}$ when the doctor came, he inserted his hand and started pulling the baby, sadly only the head came out, the entire body was left in the womb, thats when he asked us to go to the big hospital. In this hospital there was no transport (ambulance) therefore my relatives hired a tractor at a cost of 30,000/- shillings (about 15\$) that took me to the big hospital. I travelled with the baby's head out for $4 \mathrm{~h}$ all the way to the hospital. In the big hospital doctors pulled the baby using instruments. After pulling hard for long, the baby was removed, then my pelvis relaxed completely. Soon after, both urine and feaces started leaking through the vagina". ... If I got early to this hospital it would have been different, ... nurses in the village health facility were certain that I will deliver, they kept on saying wait, wait while the possibility of giving birth normally was minimal (crying...)" (Divorced, aged 33, Mbori-

Dodoma).

Other women reported experiences of waiting for a long time in the primary health care facility because nurses did not make decisions to consult with them or timely transfer them to an $\mathrm{CEmOC}$ health care facility in a timely manner after recognizing that spontaneous delivery was difficult:

"...In the health facility I spend the night until morning ... I had pains, the day passed, I slept again until morning again, and it was when a decision was made to transfer me to another hospital. They said it was because I had urine retention. On the third day is when I was transported to a big hospital" (Divorced, aged 20, Mlandizi-Pwani).

“...I stayed for a long time, and each time I called for help, the nurse would tell me to lie on my side. I continued to lie on one side until midday. Since 10 am they told me I will deliver at $2 \mathrm{pm}$. Later, my mother asked them to let us go to the main hospital, they refused saying I will deliver because membranes had ruptured already, ... but I could not" (Divorced, aged29, Ifakara-Morogoro).

Another woman who was a primigravida spent 4 days labouring in the primary health care facility before the referral decision was made:

“... it took 4 days at the village health facility, I could not give birth and then I was referred to the big hospital" (Divorced, aged 29, Kibakwe, Dodoma).

\section{Discussion}

Access to timely and quality care during labour and delivery is of paramount importance in reducing women's and neonates' mortality rates [29]. Women in this study were unable to access quality birth care because of their inability to make decisions for health care facility delivery. Health care facilities providing $\mathrm{CEmOC}$ were located far from where the women lived. Therefore, women were unable to meet transportation costs, and in some villages, public transportation was unavailable. However, women who did reach the health care facilities reported receiving low quality birth care.

Determining where a woman is to give birth is important and requires advanced planning during the pregnancy [36]. In this study, decisions on where women should go for birth care were made when the women were already in labour. It is ideal to decide on where a woman should give birth earlier in the pregnancy. To facilitate swift care-seeking behaviours for maternal health services, this decision should be known by the rest of the family. Husbands and mothers-in-law had a significant role in deciding on a place where women should give birth. This is not surprising, because in Tanzania, as is the case in other African countries, the dominant social structure is patriarchal, with the paternal side holding power in most decision-making processes [37]. This applies even to the birthing process, where the paternal family has the final say. Other studies have also documented the powerlessness of women in societies where they are usually not involved in the decisions to seek birth care either from a TBA or at a health care facility [38]. Women's failure to access adequate obstetric care at the health care facilities could be explained by their inability to make decision by themselves, living far away from health care facilities that provide CEmOC and their inability to meet transportation costs. These findings complement those of previous studies [39, 40].

Women's lack of decision-making power is commonly associated with their low socio-economic status, young age, illiteracy and unemployment [12, 39-43]. Women who participated in this study were either illiterate or had not gone beyond completing primary education. In 
addition, they were involved in unskilled, low-paying jobs or in subsistence farming. Therefore, these women had no cash of their own for emergencies unless their husbands or relatives gave it to them. Thus, money is an important determinant for accessing quality obstetric care [44].

In Tanzania, more than $90 \%$ of pregnant women attend antenatal clinics for check-ups. It is expected that birth preparedness, a major components in focused antenatal care, is taught during these visits. However, there are several reasons why women do not prepare for birth [45]. One reason might be that women do not acquire adequate knowledge on birth preparedness during antenatal care visits, or the knowledge given was of substandard. In addition, knowledge does not always influence practice [46]. Birth preparedness ensures positive outcomes for the mother and her newborn. Key elements of birth preparedness include attending the antenatal clinic for check-ups at least 4 times during pregnancy, identifying and making a plan for reaching an adequate health care facility during labour (i.e., setting aside personal funds to cover the costs of travelling to the health facility, delivering with a skilled birth attendant). Furthermore, recognising signs of complications (i.e., knowing what community resources, such as emergency transport, funds and communications, are available in the case of emergencies) and having a plan for emergencies [36].

Consistent with other studies, women in our study failed to get to a health care facility for adequate birth care in a timely manner because of the distance to the health facility, poor road conditions, inadequate or inappropriate transport, inability to pay for transportation or because public transportation was unavailable $[12,42,47-51]$. With the government's goal of increasing access to health care services by making sure that each village has a health care facility $[52,53]$, these primary health care facilities have no components of EmOC to manage obstetric emergencies [54, 55]. Therefore, women must walk long distances to the health care facilities that provide CEmOC.

Approximately $80 \%$ of maternal deaths could be prevented if, at the time of delivery, women have timely access to relatively basic maternal services and are attended to by skilled personnel [56]. A skilled attendant (a midwife or a doctor) would continuously monitor women's progress of labour using a partograph to facilitate timely decision-making and referral, which are key factors in preventing obstructed labour and thereby preventing obstetric fistula [57]. Carelessness and lack of capacity to identify and manage labour related complications, lack of communication mechanisms and lack of ambulance services that can facilitate efficient referral of women to the $\mathrm{CEmOC}$ health care facilities once the decision is made contribute to women's inability to access adequate obstetric care in a timely manner [58]. This calls for the government to increase the production of skilled attendants and upgrading primary health care facilities to provide comprehensive emergency obstetric care to ensure that all women, regardless of where they reside, can access emergency obstetric services. This will also ensure equity in health care services provision, which is a human rights agenda [59].

Getting to the health care facilities does not necessarily mean the end of the health care seeking journey. If the facility is not well equipped to handle obstetric emergencies, or does not have adequately skilled personnel to make diagnoses and swift decisions, women would still receive inadequate obstetric care. The health care system in Tanzania is organised in a referral pyramid, starting with dispensaries at the bottom and rural health centres (RHCs) that provide basic emergency obstetric care (BEmOC) and treatment of minor conditions. At the district level, there are district hospitals at the first referral level, where necessary drugs, equipment and skilled staff are available to provide CEmOC. There are also regional hospitals in each region, with the highest levels being national and specialised hospitals [53]. Although all health care facilities in Tanzania, by design, need to provide EmOC based on the level of the facility, only those of District, Regional and National hospitals provides CEmOC. Further, health care facilities in rural Tanzania suffer from critical shortages of skilled personnel that negatively affect the quality of care provided $[11,60]$. It is common to find only one nursemidwife working in a rural health care facility serving about 10,000 people $[54,61]$. When this health care provider falls sick, there will be no one left to provide care.

Because of the shortage of skilled personnel, especially in the primary health care facilities, these personnel lack professional support and have no one with whom to consult when things become difficult; thus, they are forced to get assistance from persons without any training in midwifery skills [61]. Skilled attendance is one of the key factors in reducing maternal mortality and morbidity [1]. Skilled attendants are people with midwifery skills who have been trained to proficiency in the skills necessary to manage normal pregnancies, childbirth, and the immediate postnatal period, and to identify, manage or refer women and newborns with complications [42].

Women's inability to receive adequate birth care indicates a failure of the health care delivery system, which prohibits continuity of maternity care and is a major contributing factor for maternal mortality [56, 62]. Studies of Tanzania's health care system have reported inadequacies of the health care facilities, which experience shortages of motivated, competent staff with the right attitude [61, 63]; shortages of equipment, materials, and 
supplies [64]; and poor referral systems [24]. Women in this study received inadequate birth care while they are already at the health care facility. For example, some women were asked to wait for a long time before a referral decision was made, simply because nurses failed to diagnose obstructed labour and consult, or the doctor was not around to refer a woman for comprehensive obstetric care. When women have a choice, they will go to health care facilities they perceive to provide better quality of care, regardless of distance [65]. Access to a wellequipped health care facility may be more important than other factors in determining whether a woman seeks birth care. However, such access does not completely eradicate inefficiencies in the provision of birth care, unless skilled attendants are well motivated to perform their duties.

\section{Conclusion}

Women's lack of decision-making power, long distances to health care facilities providing CEmOC, lack of money and unavailability of transportation were the primary barriers for women to give birth in health care facilities. Nevertheless, waiting for a long time in the health care facilities before the decision to refer or consult was another problem, which caused women not to access quality birth care in a timely manner. Thus, empowering women socially and financially could promote health care facility deliveries. Tanzania's government must upgrade primary health care facilities to provide $\mathrm{CEmOC}$ and increase incentives and the number of skilled personnel for women to access quality birth care. This may result in women's improved birth care experiences and reducing maternal and neonatal morbidity and mortality.

\section{Acknowledgements}

Funding for the study was from the Gender, Generation and Social Mobilization (GeSoMo) - NUFU Project of University of Bergen, Norway. The authors are greatly grateful and indebted to all participants in the study for giving their time and information during the interviews, the authors also give special thanks to the CCBRT hospitals leadership, and staff working at the fistula wards.

\section{Authors' contributions}

LTM developed the concept and the design of the study, organized, collected, analysed data, and drafted the manuscript that was critically reviewed by TWK. Both authors read and approved the final manuscript.

\section{Competing interests}

The authors declare that they have no competing interests.

\section{Ethics approval and consent to participate}

The Muhimbili University of Health and Allied Health Sciences (MUHAS) Research and Publication Committee approved ethical clearance (Ref. no. MU/RP/AECNOI.XII/57 and MU/DRP/AECNol.XII/62). Further, permissions to conduct interview were obtained from Muhimbili National Hospital (MNH) and CCBRT hospitals. Informed consent was obtained from women with obstetric fistula after they were briefed about the objectives and procedures of the study. The recruiter also explained to the women that they have the right to agree or object to their participation, or withdraw from the study at any time if they wished to do so. Special permission was obtained from the women to audio record their interviews. However, it was also made clear that any information they provided, whether orally or in writing, would be treated with strict confidentiality. No incentives were given to women for their participation in the study. However, counselling was provided for women who seemed to be in deep sorrow.

\section{Author details}

'Department of Clinical Nursing, Muhimbili University of Health and Allied Sciences, PO Box 65004, Dar es Salaam, Tanzania. ${ }^{2}$ Department of Nursing Management, Muhimbili University of Health and Allied Sciences, PO Box 65004, Dar es Salaam, Tanzania.

Received: 15 January 2016 Accepted: 19 May 2016

Published online: 22 July 2016

\section{References}

1. UNFPA: Skilled Attendance at Birth. 2014. http://files.givewell.org/files/ DWDA\%202009/Interventions/Maternal\%20Mortality/UNFPA\%20\%20Skilled\%20Attendance\%20at\%20Birth.pdf (Accesed on 22-12-2015)

2. Campbell OM. Strategies for reducing maternal mortality: getting on with what works. Lancet. 2006:368:1284-99.

3. WHO, UNICEF, UNFPA, World Bank Group and the United Nations Population Division. Trends in maternal mortality 1990 to 2015. 2015.

4. Ray S, Madzimbamuto FD, Ramagola-Masire D, Phillips R, Mogobe KD, Haverkamp M, Mokatedi M, Motana M. Review of causes of maternal deaths in Botswana in 2010. S Afr Med J. 2013;103:537-42.

5. Illah E, Mbaruku G, Masanja H, Kahn K. Causes and risk factors for maternal mortality in rural Tanzania-case of Rufiji Health and Demographic Surveillance Site (HDSS). Afr J Reprod Health. 2013;17(September):119-30.

6. Rogo KO, Ouch J, Mwalali P. Maternal mortality: diseases and mortality in sub-Saharan Africa. 2nd ed. Washington: World Bank; 2006.

7. WHO. World Health Organization partograph in management of labour. World Health Organization Maternal Health and safe motherhood programme. Lancet. 1994;994:1399-404.

8. Adam T, Lim S, Mehta S, Bhutta ZA, Fogstad H, Mathai M, Zupan J, Darmstadt GL. Cost effectiveness analysis of strategies for maternal and neonatal health in developing countries. BMJ. 2005;331:1-6.

9. WHO, UNFPA, UNICEF, AMDD: Monitoring Emergency Obstetric Care: A Handbook. Volume 30. Geneva; 2009.

10. National Bureau of Statistics and ICF Macro: Tanzania Demographic and Health Survey 2010. Dar es Salaam, Tanzania; 2011(April).

11. Olsen $\varnothing \mathrm{E}$, Ndeki $\mathrm{S}$, Norheim OF. Availability, distribution and use of emergency obstetric care in northern Tanzania. Health Policy Plan. 2005; 20:167-75.

12. Mselle LT, Kohi TW, Mvungi A, Evjen-Olsen B, Moland K. Waiting for attention and care: birthing accounts of women in rural Tanzania who developed obstetric fistula as an outcome of labour. BMC Pregnancy Childbirth. 2011;11:75.

13. Falkingham J. Inequality and changes in women's use of maternal healthcare services in Tajikistan. Stud Fam Plann. 2003;34:32-43.

14. de Bernis L. Obstetric fistula: guiding principles for clinical management and programme development, a new WHO guideline. Int J Gynaecol Obstet. 2007:99 Suppl 1:S117-21.

15. Women's Dignity Project, Engender Health. Risk and resilience : obstetric fistula in Tanzania. 2006.

16. Donnay F, Ramsey K. Eliminating obstetric fistula: progress in partnerships. Int J Gynecol Obstet. 2006;94:254-61.

17. Mselle LT, Moland K, Evjen-Olsen B, Mvungi A, Kohi TW. "I am nothing": experiences of loss among women suffering from severe birth injuries in Tanzania. BMC Womens Health. 2011;11:49.

18. Ahmed S, Holtz SA. Social and economic consequences of obstetric fistula: life changed forever? Int J Gynaecol Obstet. 2007;99(Suppl):S10-5.

19. Muleta M, Hamlin EC, Fantahun M, Kennedy RC, Tafesse B. Health and social problems encountered by treated and untreated obstetric fistula patients in rural Ethiopia. J Obstet Gynaecol Can. 2008;30:44-50.

20. UNFPA: Reproductive Health and Safe Motherhood. New York. USA; 2006

21. INFO Project: Obstetric Fistula:Ending the Silence, Easing the Suffering Baltimore, Maryland: 2004

22. Bangser M. Obstetric fistula and stigma. Lancet. 2006;367:535-6.

23. Kazaura MR, Kamazima RS, Mangi EJ. Perceived causes of obstetric fistulae from rural southern Tanzania. Afr Health Sci. 2011;11:377-82. 
24. Mselle LT, Kohi TW. Perceived health system causes of obstetric fistula from accounts of affected women in rural Tanzania: a qualitative study. Afr J Reprod Health. 2015;19:124-32.

25. Mselle LT, Kohi TW. Living with constant leaking of urine and odour: thematic analysis of socio-cultural experiences of women affected by obstetric fistula in rural Tanzania. BMC Womens Health. 2015;15:107.

26. Watt MH, Wilson SM, Joseph M, Masenga G, MacFarlane JC, Oneko O, Sikkema KJ. Religious coping among women with obstetric fistula in Tanzania. Glob Public Heal. 2014;9:516-27.

27. Mselle LT, Evjen-Olsen B, Moland KM, Mvungi A, Kohi TW. "Hoping for a normal life again": reintegration after fistula repair in rural Tanzania. J Obstet Gynaecol Can. 2012;34:927-38.

28. Pope $\mathrm{R}$, Bangser $\mathrm{M}$, Requejo $\mathrm{JH}$. Restoring dignity: social reintegration after obstetric fistula repair in Ukerewe, Tanzania. Glob Public Health. 2011;6:859-73.

29. Thaddeus S, Maine D. Too far to walk: maternal mortality in context. Soc Sci Med. 1994;38:1091-110.

30. Mselle LT: Access and quality of birth care in Tanzania: The problem of obstetric fistula and its implication. Muhimbili University of Health and Allied Sciences; 2012.

31. Dahlstrom MF. Using narratives and storytelling to communicate science with nonexpert audiences. Proc Natl Acad Sci U S A. 2014;111:13614-20.

32. Sandelowski M. Telling stories: narrative approaches in qualitative research. Image J Nurs Sch. 1991:23:161-6.

33. Kvale S. Interviews: an introduction to qualitative research interviews. 2nd ed. Melbourne: Longman; 1996.

34. Morse J. The significance of saturation. Qual Heal Res. 1995;5:147-9.

35. Mathieson CM, Barrie CM. Probing the prime narrative: illness, interviewing, and identity. Qual Heal Res. 1998;8:581-601.

36. Family Care International. Birth preparedness: an essential part of ANC counselling. Glob Health Action. 2013;103:537-42.

37. Chapagain M. Conjugal power relations and couples' participation in reproductive health decision-making: exploring the links in Nepal. Gend Technol Dev. 2006;10:159-89.

38. Pettersson KO, Christensson K, de Freitas EDGG, Johansson E. Adaptation of health care seeking behavior during childbirth: focus group discussions with women living in the suburban areas of Luanda, Angola. Health Care Women Int. 2004;25:255-80.

39. Al RA, Afifi M, Mabry RM. Women's autonomy, education and employment in Oman and their influence on contraceptive use. Reprod Health Matters. 2004;12:144-54.

40. Basu AM, Stephanson R. Low levels of maternal education and the proximate determinants of childhood mortality: a little learning is not a dangerous thing. Soc Sci Med. 2005;60:2011-23.

41. Fotso J-C, Ezeh AC, Essendi H. Maternal health in resource-poor urban settings: how does women's autonomy influence the utilization of obstetric care services? Reprod Health. 2009;6:9

42. Kumbani L, Bjune G, Chirwa E, Malata A, Odland $\emptyset \varnothing$. Why some women fail to give birth at health facilities: a qualitative study of women's perceptions of perinatal care from rural Southern Malawi. Reprod Health. 2013;10:9

43. Kinney MV, Kerber KJ, Black RE, Cohen B, Nkrumah F, Coovadia H, Nampala PM, Lawn JE. Sub-Saharan Africa's mothers, newborns, and children: Where and why do they die? PLoS Med. 2010;7:1-9.

44. Ahmed S, Creanga AA, Gillespie DG, Tsui AO. Economic status, education and empowerment: implications for maternal health service utilization in developing countries. PLoS One. 2010;5:e11190.

45. Mutiso SM, Qureshi Z, Kinuthia J. Birth preparedness among antenatal clients. East Afr Med J. 2008;85:275-83.

46. Kabakyenga JK, Östergren P-O, Turyakira E, Pettersson KO. Knowledge of obstetric danger signs and birth preparedness practices among women in rural Uganda. Reprod Health. 2011;8:33.

47. Onta S, Choulagai B, Shrestha B, Subedi N, Bhandari GP, Krettek A. Perceptions of users and providers on barriers to utilizing skilled birth care in mid-and far-western Nepal: a qualitative study. Glob Health Action. 2014;7:24580.

48. Shrestha SK, Banu B, Khanom K, Ali L, Thapa N, Stray-Pedersen B, Devkota B. Changing trends on the place of delivery: why do Nepali women give birth at home? Reprod Health. 2012;9:25.

49. Edmonds JK, Paul M, Sibley L. Determinants of place of birth decisions in uncomplicated childbirth in Bangladesh: An empirical study. Midwifery. 2012:28:554-60.
50. Kawakatsu Y, Sugishita T, Oruenjo K, Wakhule S, Kibosia K, Were E, Honda S. Determinants of health facility utilization for childbirth in rural western Kenya: cross-sectional study. BMC Pregnancy Childbirth. 2014;14:265.

51. Pembe $A B$, Carlstedt A, Urassa DP, Lindmark G, Nyström L, Darj E. Effectiveness of maternal referral system in a rural setting: a case study from Rufiji district, Tanzania. BMC Health Serv Res. 2010;10:326.

52. Ministry of Health: Second Health Sector Strategic Plan (HSSP)(July 2003-June 2008). Reform towards Delivering Quality Health Services and Client Satisfaction. Dar es Salaam, Tanzania: Ministry of Health; 2003.

53. Ministry of Health: National Health Policy. Dar es Salaam, Tanzania: Ministry of Health; 2003.

54. Spangler SA. Assessing skilled birth attendants and emergency obstetric care in rural Tanzania: the inadequacy of using global standards and indicators to measure local realities. Reprod Health Matters. 2012;20:133-41.

55. Ministry of Health and Social Welfare (MoHSW): Primary Health Care Services Development Programme 2007-2017. Dar es Salaam, Tanzania: Ministry of Health and Social welfare; 2007.

56. Ronsmans C, Graham WJ. Maternal mortality: who, when, where, and why. Lancet. 2006;368:1189-200.

57. Mwangi A, Warren C: Taking Critical Services to the Home: Scaling-up Home-based Maternal and Postnatal Care, including Family Planning through Community Midwifery in Kenya. Frontiers in Reproductive Health, Population Council. 2008(July):1-43.

58. Cham M, Sundby J, Vangen S. Availability and quality of emergency obstetric care in Gambia's main referral hospital: women-users' testimonies. Reprod Health. 2009:6:5.

59. Paul H, de Mesquita JB. Reducing maternal mortality: the contribution of the righ to highest attainable standard of health. 2007.

60. Gerein N, Green A, Pearson S. The implications of shortages of health professionals for maternal health in sub-Saharan Africa. Reprod Health Matters. 2006;14:40-50.

61. Mselle LT, Moland KM, Mvungi A, Evjen-Olsen B, Kohi TW. Why give birth in health facility? Users' and providers' accounts of poor quality of birth care in Tanzania. BMC Health Serv Res. 2013;13:174.

62. Wiklund I, Matthiesen A-S, Klang B, Ransjö-Arvidson A-B. A comparative study in Stockholm, Sweden of labour outcome and women's perceptions of being referred in labour. Midwifery. 2002:18:193-9.

63. Kwesigabo G, Mwangu MA, Kakoko DC, Warriner I, Mkony CA, Killewo J, Macfarlane SB, Kaaya EE, Freeman P. Tanzania's health system and workforce crisis. J Public Health Policy. 2012;33 Suppl 1:S35-44.

64. Mkoka DA, Goicolea I, Kiwara A, Mwangu M, Hurtig A-K. Availability of drugs and medical supplies for emergency obstetric care: experience of health facility managers in a rural District of Tanzania. BMC Pregnancy Childbirth. 2014;14:108.

65. Kruk ME, Mbaruku G, McCord CW, Moran M, Rockers PC, Galea S. Bypassing primary care facilities for childbirth: a population-based study in rural Tanzania. Health Policy Plan. 2009;24:279-88.

\section{Submit your next manuscript to BioMed Central and we will help you at every step:}

- We accept pre-submission inquiries

- Our selector tool helps you to find the most relevant journal

- We provide round the clock customer support

- Convenient online submission

- Thorough peer review

- Inclusion in PubMed and all major indexing services

- Maximum visibility for your research

Submit your manuscript at www.biomedcentral.com/submit 